\title{
Correction to: The Mostela: an adjusted camera trapping device as a promising non-invasive tool to study and monitor small mustelids
}

\author{
Jeroen Mos $^{1,2} \cdot$ Tim Ragnvald Hofmeester ${ }^{1,3}$ (D) \\ Published online: 6 September 2021 \\ (c) Mammal Research Institute, Polish Academy of Sciences, Bialowieza, Poland 2021
}

\section{Correction to: Mammal Research}

https://doi.org/10.1007/s13364-020-00513-y

In the original published version of this article, in the first sentence of the results, we accidentally reported the wrong number of camera trapping nights in our study. The correct sentence should be "We obtained a total of 5791 recordings during 2255 trap nights (568 trap nights in 2017 and 1687 in 2018)". All other information (including the reported trapping rates) is correct, as we calculated trapping rates, and did all modelling, with the correct number of trap nights.

The original article has been corrected.

Publisher's note Springer Nature remains neutral with regard to jurisdictional claims in published maps and institutional affiliations.

The original article can be found online at https://doi.org/10.1007/ s13364-020-00513-y.

Tim Ragnvald Hofmeester

tim.hofmeester@slu.se

1 Dutch Small Mustelid Foundation, Goudreinette 10, 6922 AE Duiven, The Netherlands

2 Mos Ecologisch Advies en Onderzoek, Goudreinette 10, 6922 AE Duiven, The Netherlands

3 Department of Wildlife, Fish, and Environmental Studies, Swedish University of Agricultural Sciences, Skogsmarksgränd 7, 90736 Umeå, Sweden 